\title{
Waits increasing for some priority surgeries
}

Cite as: CMAJ 2018 April 30;190:E552. doi: 10.1503/cmaj.109-5593

Posted on cmajnews.com on Apr. 12, 2018.

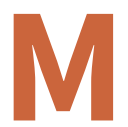

ore Canadians are getting joint replacements and cataract surgery, but they're also waiting longer for the procedures than they were three years ago, according to new data from the Canadian Institute for Health Information (CIHI). Meanwhile, waits for more urgent procedures, such as hip-fracture repair and radiation therapy, have held steady.

Last year, the percentage of patients who received hip and knee replacements within the recommended six months dropped to $76 \%$ and $69 \%$, respectively, down from $81 \%$ and $77 \%$ in 2015 . Wait times for cataract surgery also increased in seven of 10 provinces over the same period. Seventy-one percent of patients received the surgery within 16 weeks in 2017, down from 76\% in 2015.

It's a "meaningful change in the data," said Jennifer D'Silva, manager of emerging issues at $\mathrm{CIHI}$. Back in 2008, about $80 \%$ of patients were receiving these procedures within recommended wait times. The trend is also consistent across most provinces, with a few exceptions. "For example, Quebec has maintained their wait times compared to three years ago, and generally their wait times are shorter than the national average, and in Nova Scotia, we don't see a change from previous years."

Despite longer waits, "more people are getting these surgeries done," D'Silva said. The number of hip replacements performed in Canada increased 7\% since

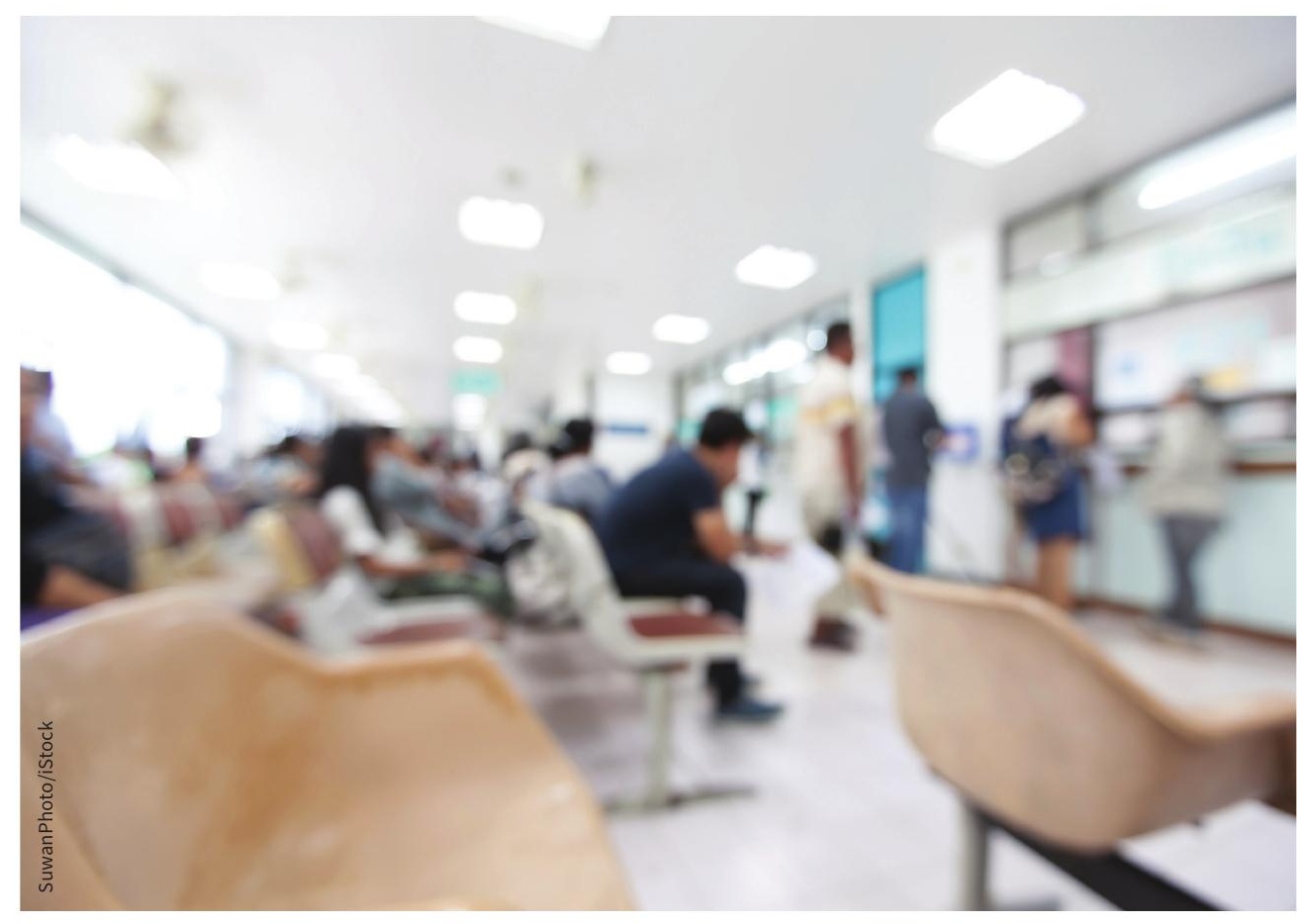

Fewer Canadians are receiving surgery for cataracts and hip and knee replacements within recommended wait times.

2015, while knee replacement and cataract surgeries increased $6 \%$ and $3 \%$, respectively. The aging population and improved technology may be driving up demand for the surgeries, D'Silva explained. The availability of surgeons, operating room time and postoperative beds also affect waits times, she said.

However, D'Silva noted that waits are holding steady for "more medically urgent, time-sensitive" procedures. Eighty-seven percent of patients received hip-fracture repair within the recommended 48 hours in 2017, the same as in 2015. Wait times for radiation therapy were likewise unchanged: $97 \%$ of patients received the treatment within the benchmark of 28 days.

\section{Lauren Vogel, CMAJ}

